\title{
Experimental and Computational Study of Melting of Paraffin Wax Inside a Cylindrical Capsules of Elliptical Cross Section.
}

\author{
Mohamed. A. Sultan ${ }^{1}$, E. A. El-Negiry ${ }^{2}$, H. M. Mustafa ${ }^{3}$ and A.M. El-Boz ${ }^{2}$ \\ ${ }^{I}$ M.Sc. Teaching assistant, Mechanical engineering Dept, Future Institute of Engineering and \\ Technology, Talkha Egypt. \\ ${ }^{2}$ Mech. Power Eng. Dept, Faculty of Engineering, Mansoura University, Mansoura, Egypt. \\ ${ }^{3}$ Mech. Eng. Dept., Higher Technological Institute, $10^{\text {th }}$ of Ramadan, Asharqia, Egypt.
}

\begin{abstract}
This paper focuses on the melting of phase change material capsulated in the elliptical cross-section horizontal cylinder under convective boundary conditions. Different parameters are discussed namely, the HTF inlet temperature and velocity and the aspect ratio of the capsule cross-section. The effect of HTF inlet temperature, inlet velocity, and encapsulant aspect ratio was studied using the CFD software FLUENT6.3.26. A comparison between the numerical and experimental results was made for the system. The experimental results matched well with the heat transfer model. It is shown that the inlet temperature of the heat transfer fluid (HTF) has a great effect on the process of paraffin wax melting. The increase of HTF inlet temperatures increases the PCM liquid fraction and decreases at the same time the total time of melting the capsulated paraffin wax. The geometry of the capsule cross-section represented by its aspect ratio has a sensible effect on the process of paraffin wax melting. Decreasing the aspect ratio of the capsule, i.e elongated the capsule in the direction of flow increasing the PCM liquid fraction and decreases the total time of melting the capsulated paraffin wax. The increase of HTF inlet velocity has a very weak effect on the process of paraffin wax melting.
\end{abstract}

Keywords: encapsulated, PCM, heat transfer, melting time.

Nomenclature

\begin{tabular}{|l|l|}
\hline A: Surface area of test tube, $\mathrm{m} 2$ & Greek Symbols \\
\hline $\mathrm{Cp}:$ Specific heat at constant pressure, J/kg. K & $\beta:$ volumetric expansion coefficient $\left(\mathrm{K}^{-1}\right)$ \\
\hline $\mathrm{D}:$ Diameter, $\mathrm{m}$ & $\Delta \mathrm{H}:$ Latent heat, $\mathrm{J} / \mathrm{kg}$ \\
\hline $\mathrm{E}:$ Total energy stored, $\mathrm{kJ} / \mathrm{kg}$ & $\lambda:$ Liquid fraction $(\%)$ \\
\hline $\mathrm{g}:$ : Acceleration of gravity, $\mathrm{m} / \mathrm{sec}^{2}$ & $\mu:$ Dynamic viscosity, $\mathrm{kg} / \mathrm{m} . \mathrm{s}$ \\
\hline $\mathrm{H}:$ Total enthalpy, $/ \mathrm{kg}$ & $\mathrm{LHS}:$ Latent heat storage \\
\hline $\mathrm{h}:$ Sensible enthalpy, $\mathrm{J} / \mathrm{kg}$ & $\mathrm{PCM}:$ Phase change material \\
\hline $\mathrm{k}:$ Thermal conductivity, W/m. K & $\mathrm{t}:$ Time, $\mathrm{s}$ \\
\hline $\mathrm{L}:$ Latent heat of fusion, $\mathrm{J} / \mathrm{kg}$ & $\overrightarrow{\mathrm{V}}:$ Velocity vector \\
\hline $\mathrm{Q}:$ Heat transfer rate, $\mathrm{W}$ & $\mathrm{q}:$ Heat flux, W/m2 \\
\hline$\rho:$ Density, kg/m3 & $\vec{S}:$ Source term \\
\hline Abbreviations & HTF: Heat transfer fluid \\
\hline CFD : Computational fluid dynamic & SHS: Sensible het storage \\
\hline EPCM: Encapsulated Phase change material & TES: Thermal energy storage \\
\hline
\end{tabular}

\section{INTRODUCTION}

Because of their thermal properties, Phase change materials are frequently used in thermal systems. These materials can absorb and release large amounts of heat with a small change in temperature and density (have a high rate of fusion). This heat is named latent heat of phase change material (PCM) because heat can be absorbed or released during a liquid-solid phase change. PCM is used in multiple disciplines for latent heat storage such as solar thermal energy [1] in buildings [2], heat pumps, and spacecraft[3]. Due to its low thermal conductivity, the use of PCM has been limited [4].

Research has been conducted on phase change materials with an application in thermal systems. Various sizes and shapes of enclosures have been 


\section{Mohamed. A. Sultan, E. A. El-Negiry, H. M. Mustafa and A.M. El-Boz "Experimental and Co..."}

studied experimentally and analytically. Many researches were performed to investigate the melting and solidification of PCM packed inside capsules with cylindrical, tubular, spherical and rectangular cross-section shapes summarized in the following paragraphs.

It is observed that encapsulation geometry has a substantial effect on the heat transfer characteristics of the PCM. A survey of the effect of various encapsulation geometries on the heat transfer characteristics is provided below. Wei et al. [5] performed numerical and experimental studies on various geometries of encapsulated PCMs, namely, sphere, cylinder, plate, and tube to improve the heat transfer rate. It was reported that the spherical shape resulted in the highest heat transfer rate. For other geometries, the heat transfer rate decreased in the order of cylinder, plate, and tube. Kalaiselvam Siva et al. [6] analyzed geometries filled with the same volume of PCM and concluded a cylinder provides a better encapsulation than a sphere. The cylinder has $38 \%$ more surface area than sphere thereby giving a $47 \%$ reduction in complete solidification time. The dimensions of the selected cylinder were such that the radius is not as large as it would lead to an increase in solidification time. Hence selection of configuration plays a vital role in thermal energy storage (TES) systems.

Although several experimental and numerical studies have been devoted to convection dominated melting of a PCM for various geometric configurations, particular attention is given to melting in a horizontal cylinder as a model for thermal energy storage system [7-9]. Several numerical and analytical studies have been performed in an attempt to model the melting phenomenon in a horizontal cylinder based on the Boussinesq approximation [10-14]. Saitoh and Hirose [10] presented experimental results that show a convexed solid-liquid interface at the bottom of the unmelted solid during the melting process. Rieger et al. [11], Ho and Viskanta [12] and Yoo and Ro [13] investigated experimentally the evolution of the solid-liquid interface during the melting of a PCM contained in a horizontal cylinder. They showed a concaved interface numerically and experimentally. Prasad and Sengupta [14] studied numerically the unconstrained melting of a PCM inside an isothermal horizontal tube. The model evaluated the irregular, temporal shape of the solid-liquid interface, the downward traveling motion of solid PCM due to density difference, and natural convection in the liquid phase.

Agyenim et al [15] reported that cylindrical and rectangular shapes are the most commonly used container shapes for the enhanced heat transfer between the PCM and heat transfer fluid (HTF). A shell and tube arrangement found to give minimal heat loss.

Palanisamy and Niyas [16] developed a thermal model to compare the performance of latent heat storage (LHS)/ sensible heat storage (SHS) capsules of different geometrical configurations. Numerical results showed that for the same mass of storage material, cylindrical configuration yields lesser charging time than the spherical configuration. This is because the distance between the center and periphery of the capsule is more in a spherical capsule than that of a cylindrical capsule. In the cylindrical models, configuration with a higher aspect ratio takes lesser time for charging.

Different methods for measuring phase change have been used in experiments using PCM. One method is to capture the phase change photographically and determine its location using digital image processing techniques [17]. Other methods include periodically weighing the PCM [18-19] or measuring the density change of the PCM [20].

To the knowledge of the authors the horizontal capsules of the elliptical cross-section with different aspect ratio not investigated yet.

The objective of this research is to characterize the melting processes of phase-change materials in centimeter-scale cylindrical capsules of elliptical cross-sections with a convective boundary condition. Effect of aspect ratio, inlet temperature and inlet velocity of heat transfer (HTF) on melting time and liquid fraction of molten paraffin will be investigated.

\section{Experimental test rig}

An experimental set up was designed and manufactured in Air conditioning laboratory mechanical power engineering department faculty of engineering Mansoura University. This set up was built to validate the theoretical solution for the melting of phase change materials (PCMs) using the Fluent program.

The test rig consists as shown in Fig. (1) of a cube tank (10) made of galvanized steel sheet with dimensions of $30 \mathrm{~cm} * 30 \mathrm{~cm}$ and $30 \mathrm{~cm}$ height. The tank is used to supply the test section with hot water (11) at different temperatures. The tank is insulated with glass wool insulation to decrease the heat loss from hot water in the tank. The tank is equipped with a $1 \mathrm{~kW}$ electric heater (12) connected to the electrical main supply with a voltage cutoff adapter that provides a voltage variation from 0 to $220 \mathrm{~V}$ to adjust the water temperature in the tank at a predefined temperature. 


\section{Mohamed. A. Sultan, E. A. El-Negiry, H. M. Mustafa and A.M. El-Boz "Experimental and Co..."}

The reservoir is equipped with a small 100-Watt pump (8) connected to the tank bottom to supply the test section with hot water required to heat the capsule at different velocities using valve (7) which regulates the water discharge rate to the test section (1).

The test section (1) is a cup shape $10 \mathrm{~cm}$ height. Hot water is brought to it via a $1 / 4 \backslash \backslash$ pipe diameter welded in the bottom of a tapered section (6) through the pump (8). To drain the water into the hot water tank, a hole of $1 / 4 \backslash \backslash$ diameter was used and a tube (9) of the same diameter was welded $1 \mathrm{~cm}$ below the top of the cup-shape to return the water to the hot water tank. The capsule (3) filled with PCM is placed in a horizontal position using a 1 $\mathrm{mm}$ diameter wire carrier. The capsule is a $4-\mathrm{cm}-$ diameter, 6-cm-long Pyrex glass cylinder filled with the molten paraffin, then left to cool and closed with its lid.

To facilitate the vision and image of the capsule, the test section was provided with two sight glass (4) tabs on opposite sides of the test section and perpendicular to the capsule axis. To measure the average temperature of the water before and after the capsule, 3 thermocouples (5) were fixed regularly $20 \mathrm{~cm}$ under the capsule and 3 others (2) 2 $\mathrm{cm}$ over the capsule. The rate of hot water passing through the test section was measured by the amount of water collected at a given time during the experiment..

\section{Numerical Modeling}

The thermal model describing this system is based on the following assumptions: (1) the fluid flow is laminar and incompressible and the flow rate is constant with time; (2) the heat transfer is one dimensional; (3) heat loss to the surroundings is neglected; (4) thermophysical properties of PCM and HTF are temperature independent; (5) the convection effects present in the melting of the PCM are taken into account via the use of an effective thermal conductivity keff in the energy equation;(6) because of the temperature difference between the HTF and the exposed surface of the capsules, the heat is transferred between them by convection.

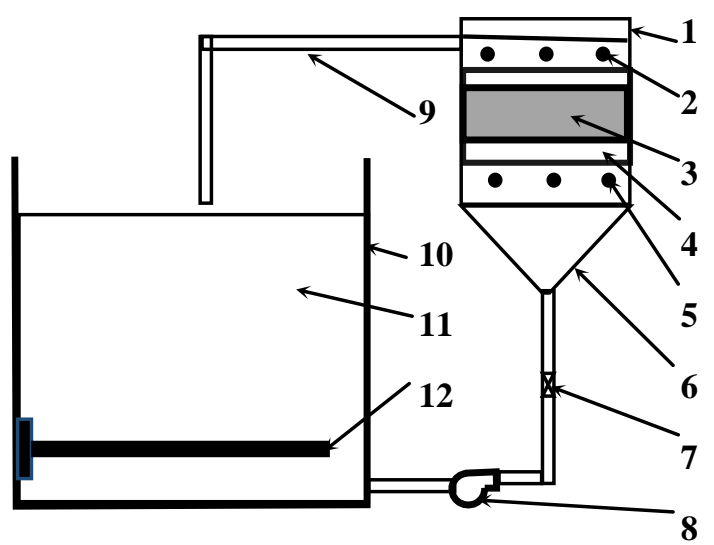

1-Test section 2-Thermocouples 3-PCM Capsule 4-Sight glass 5-Thermocouples 6-Transition section 7-regulation valve 8-Water pump 9-Return water tube 10-Water tank 11-Hot water 12- Electric heater.

Fig (1) Layout of the test rig

Fig. (2) shows the physical representation of the system considered for the analysis. An insulated duct of height $0.3 \mathrm{~m}$ and cross-section of width twice the ellipse's horizontal ax (a) and a length of $1 \mathrm{~m}$ is used. The PCM capsules have horizontal and vertical axes $a$ and $b$ respectively laying with its center line on the centerline of the tank.

The HTF that inter from the bottom flows around the elliptical cross-sectional capsule and exit from the top of the tank is water and the PCM is commercial grade paraffin wax. The phase change temperature, latent heat of fusion and other thermophysical properties are shown in table 1 . During the charging process (or melting of the $\mathrm{PCM}$ ), the HTF temperature at the inlet is maintained constant above the phase change temperature of the PCM, and velocity also is kept constant.

A numerical solution is carried out using the CFD software ANSYS FLUENT 2019 R2 to solve the melting model and energy equation in three steps. Firstly, the geometry is created with GAMBIT software and the cylindrical space is treated as fluid (PCM). Secondly, a mesh is created by discretizing the computational domain into different mesh elements to maintain minimum skewness. The convergence criterion of 10-6 is used for the studied case. Thirdly, the physical parameters for a 2-Dimension axisymmetric model (PCM) used in this study, The stored energy is in two forms sensible and latent heat. Sensible heat plays a major role in regions where the temperature of PCM is below $329 \mathrm{~K}$, or above $331 \mathrm{~K}$ and between these two temperatures the latent heat is dominated. The thermophysical properties of paraffin wax showed in table (1). 


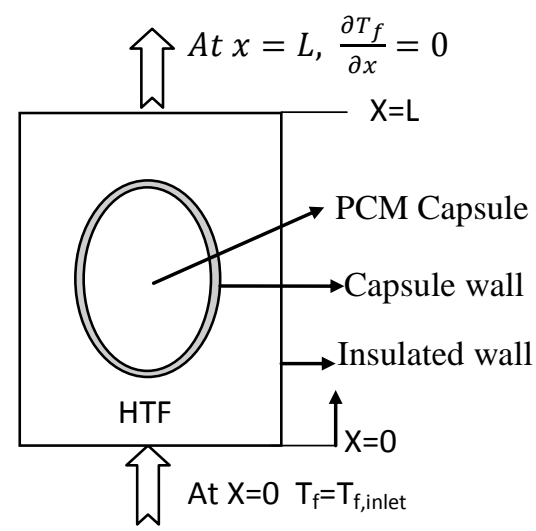

Fig.( 2 ) Thermal storage model for configuration numerical analysis.

Table (1) Thermo physical properties of paraffin wax.

\begin{tabular}{|l|l|l|}
\hline Property & Solid & Liquid \\
\hline $\begin{array}{l}\text { Thermal conductivity } \\
\mathrm{W} / \mathrm{m} . \mathrm{K}\end{array}$ & 0.15 & 0.147 \\
\hline $\begin{array}{l}\text { Heat capacity } \\
\mathrm{kJ} / \mathrm{kg} \mathrm{K}\end{array}$ & 2.354 & 2.44 \\
\hline density kg/m ${ }^{3}$ & 890 & 712 \\
\hline $\begin{array}{l}\text { Dynamic viscosity } \\
\text { Pa. s }\end{array}$ & -------- & 0.0052 \\
\hline $\begin{array}{l}\text { Coefficient } \\
\text { thermal expansion K- } \\
1\end{array}$ & ------- & 0.000714 \\
\hline $\begin{array}{l}\text { Saturation } \\
\text { temperature, K }\end{array}$ & 329 & 331 \\
\hline Latent heat $\mathrm{kJ} / \mathrm{kg}$ & 259 & \\
\hline
\end{tabular}

\section{Governing Equations}

The change of phase process is simulated using the enthalpy-porosity model formulated by Voller $[21,22]$. In this model, the liquid-solid mushy zone is treated as a porous zone with the same porosity as the liquid fraction. The liquid fraction, 1, is defined as the fraction of the volume that is in liquid form. Porosity ranges between 0 and 1 , depending on the progress of the phase-change process. The liquid fraction is computed at each iteration, based on the enthalpy balance. When the material has fully solidified in a cell, its porosity becomes zero, resulting in the drop in velocities to zero. This behavior of the interface in terms of Darcy's law damping mechanism is included as a source term in the momentum equation due to the effect of the phase change on convection.

The summation of the sensible enthalpy, $h$, and latent heat, $\Delta \mathrm{H}$ is the total enthalpy of the material:

$$
\mathrm{H}=\mathrm{h}+\Delta \mathrm{H}
$$

The latent heat can be written in terms of the latent heat of the material, L:

$$
\Delta \mathrm{H}=\lambda * \mathrm{~L}
$$

Where $\Delta \mathrm{H}$ may vary from zero (solid) to L (liquid), therefore, the liquid fraction, $\lambda$ can be defined as:

$$
\begin{aligned}
& \lambda=\frac{\Delta \mathrm{H}}{\mathrm{L}}=0 \quad \text { for } \mathrm{T}<\mathrm{T}_{\text {solid }} \\
& \lambda=\frac{\Delta \mathrm{H}}{\mathrm{L}}=1 \text { for } \mathrm{T}>\mathrm{T}_{\text {Liquid }} \\
& \lambda=\frac{\Delta \mathrm{H}}{\mathrm{L}}=\frac{\mathrm{T}-\mathrm{T}_{\text {solid }}}{\mathrm{T}_{\text {liquid }}-\mathrm{T}_{\text {solid }}} \\
& \text { for } \mathrm{T}_{\text {solid }} \leq \mathrm{T} \leq \mathrm{T}_{\text {liquid }}
\end{aligned}
$$

Energy equation

The energy equation for the melting model is written as [21].:

$\frac{\partial}{\partial \mathrm{t}}(\rho \mathrm{H})+\nabla \cdot(\rho \overrightarrow{\mathrm{V}} \mathrm{H})=\nabla \cdot(\mathrm{k} \nabla \mathrm{T})+\mathrm{s}$

The solution for temperature is principally an iteration between the energy equation and the liquid fraction equation.

Continuity equation :

$$
\nabla \cdot \vec{V}=0
$$

Momentum equation

The enthalpy-porosity technique treats the mushy zone as a porous medium. The porosity in each cell is set equal to the liquid fraction in that cell. In fully solidified regions, the porosity is equal to zero, which extinguishes the velocities in these regions. The momentum sink damping term $\overrightarrow{\mathrm{S}}$ that is added to the momentum due to phase change effect on convection is [21]:

$$
\vec{S}=-\frac{\left(1-\lambda^{2}\right)}{\left(\lambda^{3}-\varepsilon\right)} A_{\text {mush }} \vec{V}
$$

Where $\lambda$ is the liquid fraction, $\varepsilon$ is the mushy zone constant, it is a small number (0.001) to avoid division by zero.

The momentum equation for the melting problem is written as [21]:

$$
\begin{aligned}
\frac{\partial \overrightarrow{\mathrm{V}}}{\partial \mathrm{t}}+\overrightarrow{\mathrm{V}} \cdot \nabla \overrightarrow{\mathrm{V}}=\frac{1}{\rho} & \left(-\nabla \mathrm{P}+\mu \nabla^{2} \overrightarrow{\mathrm{V}}\right. \\
& \left.+\rho \beta \overrightarrow{\mathrm{g}}\left(\mathrm{T}-\mathrm{T}_{\text {ref }}\right)\right)+\overrightarrow{\mathrm{S}}
\end{aligned}
$$

The elliptical section is drawn in the GAMBIT software program so that the aspect ratio can be changed to any desired value, including an aspect ratio of 1 which represents the circular crosssection. It is easy to compare the experimental results with the theoretical one because it is 
difficult to obtain a Pyrex glass capsule with the elliptical cross-section to be tested experimentally to make validation of the theoretical results.

\section{Results and discussion}

In this section, we will discuss a suitable grid size and compare the experimental and theoretical results to validate the theoretical solution.

\section{Grid Independent Test}

Free triangular mesh has been adapted in the numerical model. To test the dependency of numerical results on the mesh element size a simulation is run with a circular cylindrical capsule of $4 \mathrm{~cm}$ diameter and $6 \mathrm{~cm}$ length. The capsule is initially at $300 \mathrm{~K}$. At any time $\mathrm{t}>0$, the boundary of the capsule is at $343 \mathrm{~K}$. The average temperature and liquid fraction of the capsule are compared for different element sizes and it is observed from Figs. ( 3 and 4 ) that mesh size of $0.00035 \mathrm{~m}$ can be taken for the numerical model. Similarly, a grid independency test carried has been carried out for other configurations also. The time steps used in the analysis is $0.5 \mathrm{~s}$ throughout all models.

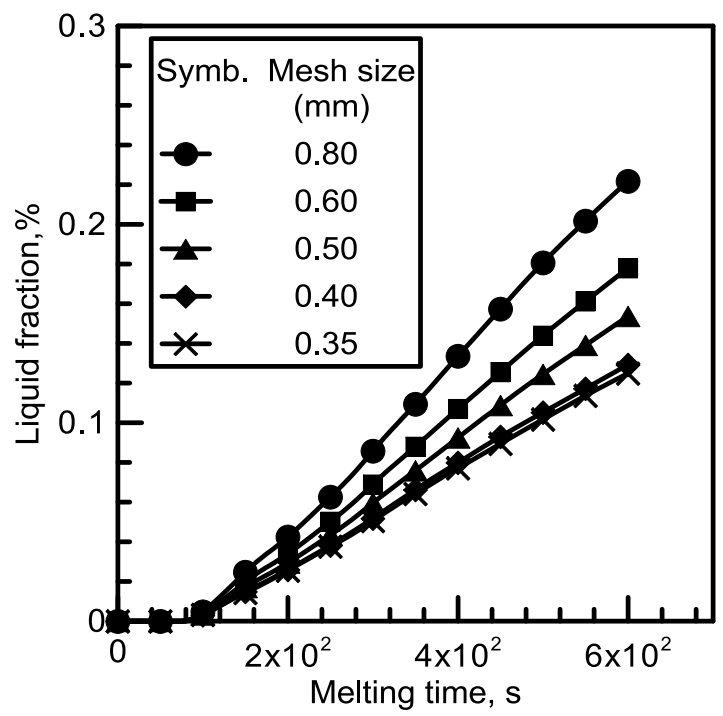

Fig.(3) Effect of mesh size on PCM liquid fraction at constant HTF inlet temperature of $343 \mathrm{~K}$ and velocity of $0.003 \mathrm{~m} / \mathrm{s}$.

\section{Validation of theoretical results}

In this section, we will compare the experimental results of circular cross-section capsule $4 \mathrm{~cm}$ in diameter and $6 \mathrm{~cm}$ in length with the theoretical results of a capsule of the same shape and dimensions, obtained from the numerical model. Fig. ( 5) illustrates as a contour the variation of the liquid fraction of PCM melting with the pictures that captured during the experiments for HTF initial temperature of $346.4 \mathrm{~K}$ and velocity of $0.006 \mathrm{~m} / \mathrm{s}$.

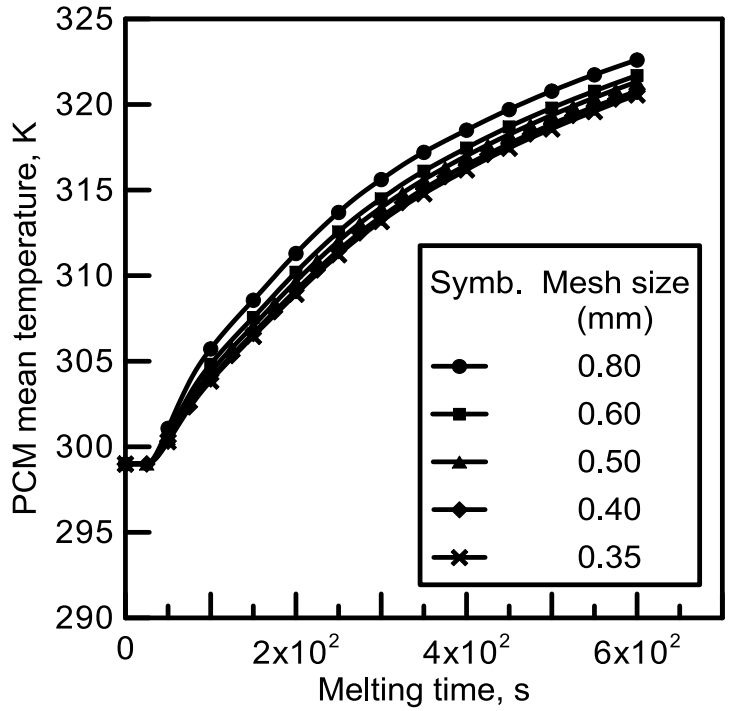

Fig.(4) Effect of mesh size on PCM mean temperature at constant HTF inlet temperature of $343 \mathrm{~K}$ and velocity of $0.003 \mathrm{~m} / \mathrm{s}$

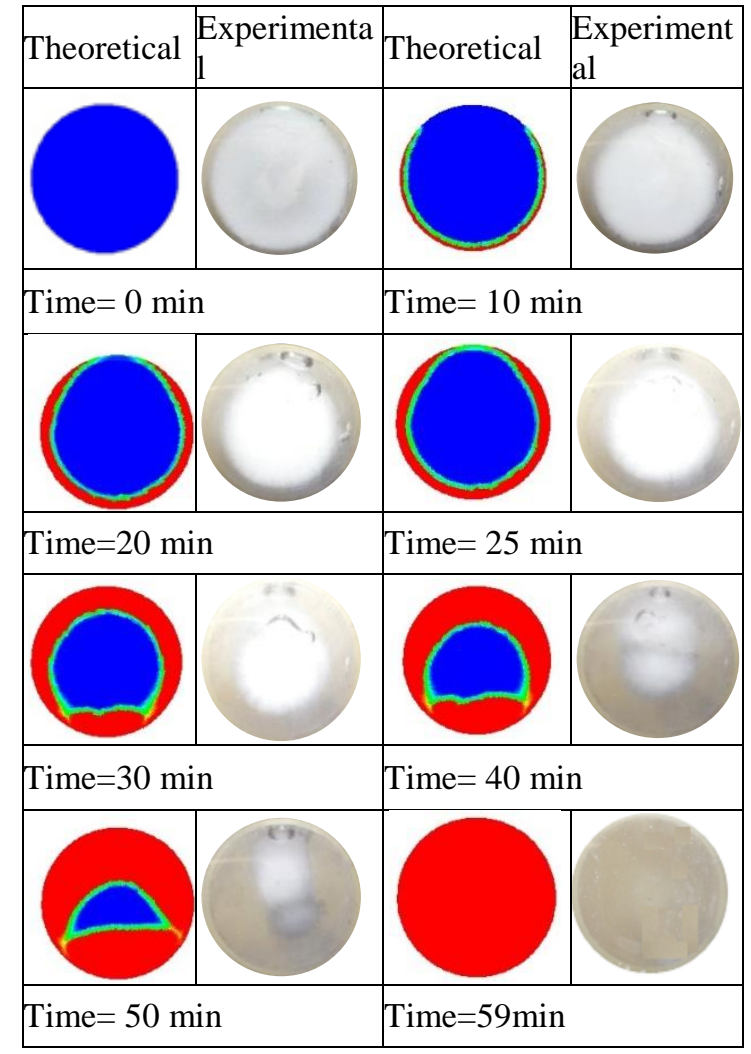

Figure ( 5 ) Comparison between liquid fraction Contours and camera photos of paraffin wax at different time for HTF inlet temperature of $343 \mathrm{~K}$ and mean velocity of $0.003 \mathrm{~m} / \mathrm{s}$

It is shown from the figure that there is a fair agreement between the experimental and theoretical results and the shape of molten and solid paraffin. The fair agreement between experimental and theoretical results ensures the 
validity of the theoretical model and the accuracy of different thermal properties of the paraffin wax.

Comparison between circular and elliptical capsules

Fig. (6) shows the relation between liquid fraction and time for circular cross-section capsule and elliptical cross-section one of the same crosssectional area and length. The diameter of the circular capsule is $4 \mathrm{~cm}$ and aspect ratio (Ar) of the elliptical capsule is 2 . The boundary conditions are at an inlet HTF temperature of $343 \mathrm{~K}$ and inlet HTF mean velocity of $0.003 \mathrm{~m} / \mathrm{s}$. It is seen from the figure that the total melting time of the elliptical capsule is lesser than that for the circular one. This is due to the increase in capsule surface area and different flow characteristics of HTF.

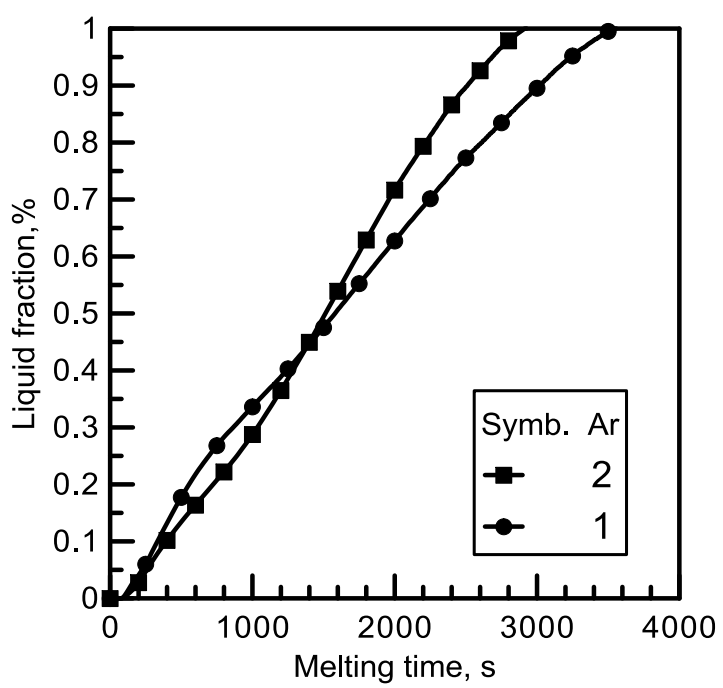

Fig.(6) Comparison of PCM liquid fraction for circular and elleptical cross sections of the same area at constant HTF inlet temperature of $343 \mathrm{~K}$ and velocity of $0.003 \mathrm{~m} / \mathrm{s}$.

Effect of discussed parameters

Because the total melting time of the capsule of aspect ratio 2 was less than that for circular capsule we will discuss the effect of the aspect ratio of the elliptical cross section-capsule, the inlet temperature and velocity of the heat transfer fluid (HTF) in this section.

\section{Effect of HTF inlet temperature}

The variations of PCM liquid fraction stored energy and mean temperature with charging time and HTF inlet temperature are plotted in Figs. 7-9, for a capsule with an aspect ratio of 0.81 . The figures show that the higher the HTF inlet temperature the higher the liquid fraction, stored energy and mean temperature of paraffin wax at the same charging time. The figures also show that liquid fraction stored energy and mean temperature of paraffin wax increase with charging time at the same HTF inlet temperature.
Figure 10, shows the relationship between total melting time and HTF inlet temperature for aspect ratio of 0.81 and HTF inlet velocity of $0.003 \mathrm{~m} / \mathrm{s}$ It is clear from the figure that the total melting time decreases with the increase of HTF inlet temperature. This is due to the increase in HTF temperature increases the temperature difference between the HTF and the PCM which is the motive force of heat transfer.

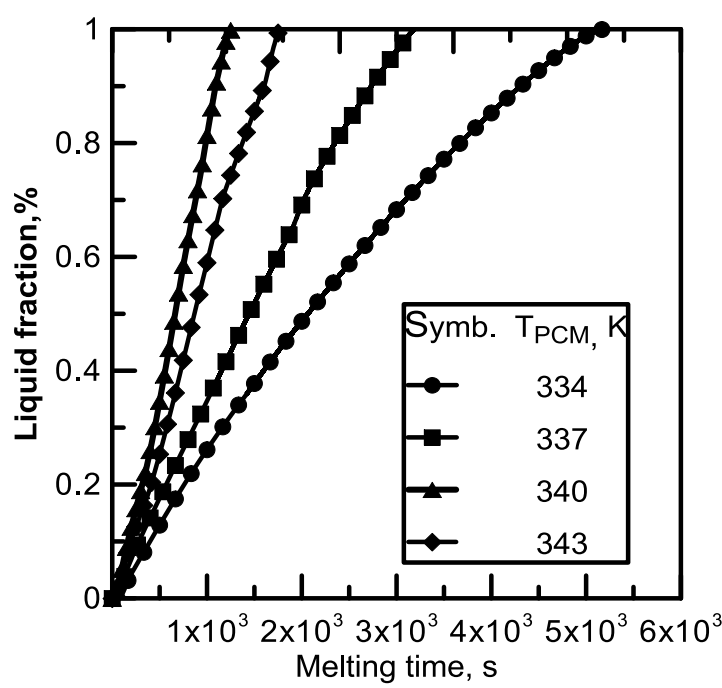

Fig. 7 ) Effect of HTF inlet temperature on PCM liquid fraction at constant aspect ratio of 0.81 and HTF inlet velocity of $0.003 \mathrm{~m} / \mathrm{s}$.

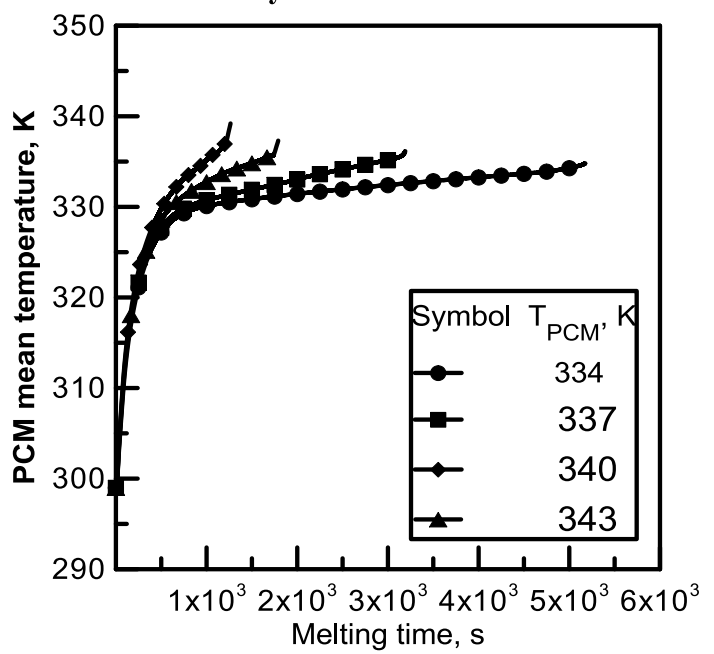

Fig. ( 8 ) Effect of HTF inlet temperature on PCM mean temperature at constant aspect ratio of 0.81 and HTF inlet velocity of $0.003 \mathrm{~m} / \mathrm{s}$. 


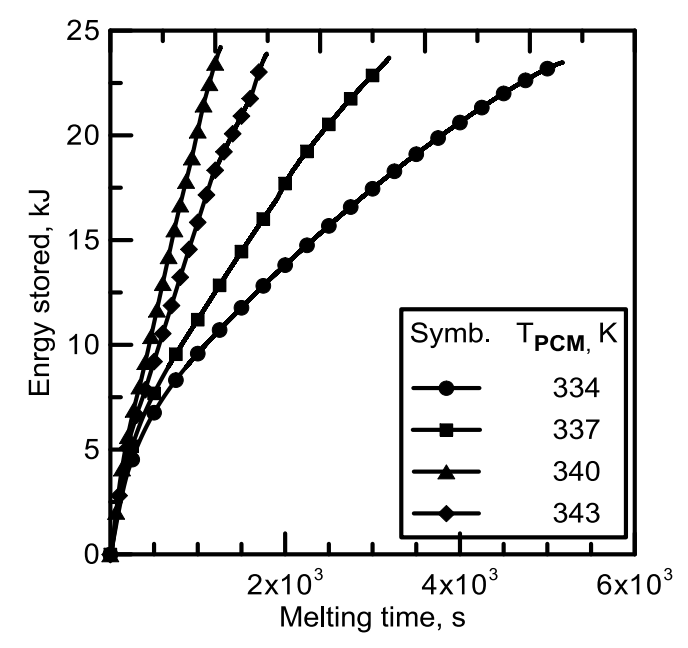

Fig. ( 9 ) Effect of HTF inlet temperature on PCM enrgy stored at constant aspect ratio of 0.81 and HTF inlet velocity of $0.003 \mathrm{~m} / \mathrm{s}$.

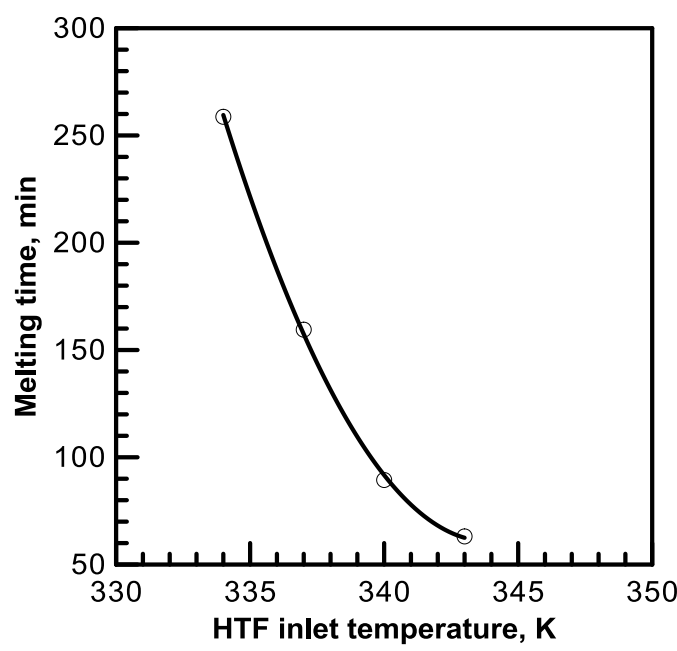

Fig.( 10 ) Effect of HTF inlet temperature on PCM total melting time at capsule aspect ratio of 0.81 and velocity of $0.003 \mathrm{~m} / \mathrm{s}$.

\section{Effect of HTF inlet velocity}

PCM liquid fraction stored energy and mean temperature as a function of charging time are plotted in Figs. 11-13. The aspect ratio is kept constant at 0.81 , HTF inlet temperature is equal to $343 \mathrm{~K}$ and HTF inlet velocity is varied from 0.003 to $0.012 \mathrm{~m} / \mathrm{s}$. It is shown from the figures that the liquid fraction, stored energy and mean temperature of paraffin wax slightly increase with HTF inlet velocity at the same charging time.

The figures also indicate that liquid fraction, stored energy and mean temperature of paraffin wax increase with charging time at the same HTF inlet velocity.

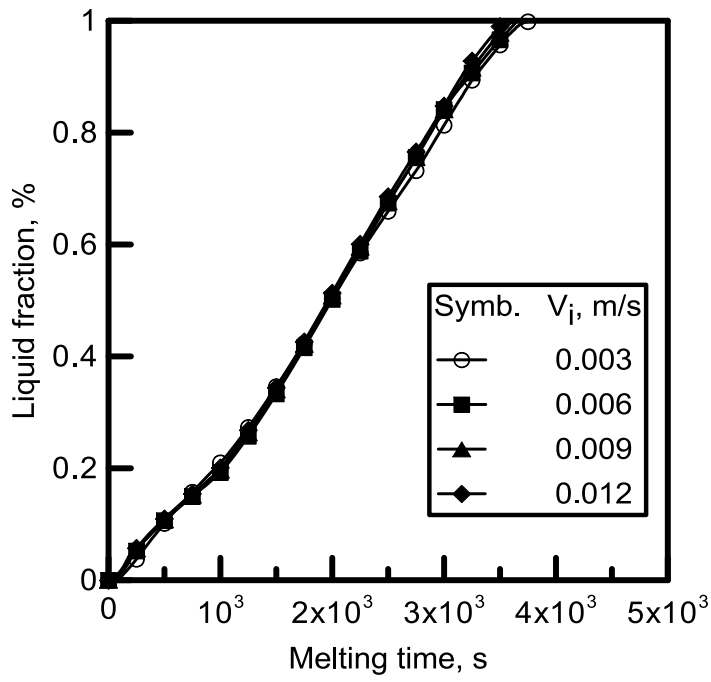

Fig.(11) Effect of HTF inlet velocity on PCM liquid fraction at constant HTF inlet temperature of $343 \mathrm{~K}$ and aspect ratio of 0.81 .

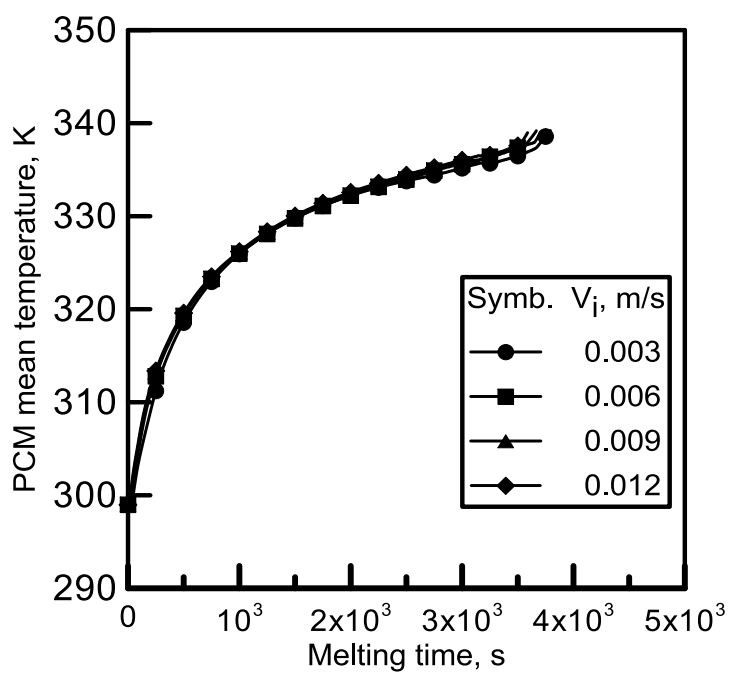

Fig.(12) Effect of HTF inlet velocity on PCM mean temperature at constant HTF inlet temperature of $343 \mathrm{~K}$ and aspect ratio of 0.81 .

Figure 14, illustrates the relationship between total melting time and HTF inlet velocity for aspect ratio of 0.81 and HTF inlet temperature of $343 \mathrm{~K}$, It is seen from the figure that the total melting time slightly decreases with the increase of HTF inlet velocity. This is because increasing the HTF inlet velocity decreases the outside heat transfer resistance only while the other thermal resistances of PCM is still very small compared to it, so the effect of HTF velocity is very small. 


\section{Effect of Aspect ratio}

Figs. 15-17 show the variations of PCM liquid fraction, stored energy and mean temperature with charging time and PCM capsule aspect ratio, for constant HTF inlet temperature of $343 \mathrm{~K}$ and inlet velocity of $0.003 \mathrm{~m} / \mathrm{s}$. One can see from the figures that the capsule aspect ratio has a significant effect on the liquid fraction, stored energy and mean temperature of paraffin wax at the same charging time. The figures also show that liquid fraction stored energy and mean temperature of paraffin wax increase with charging time at the same capsule aspect ratio.

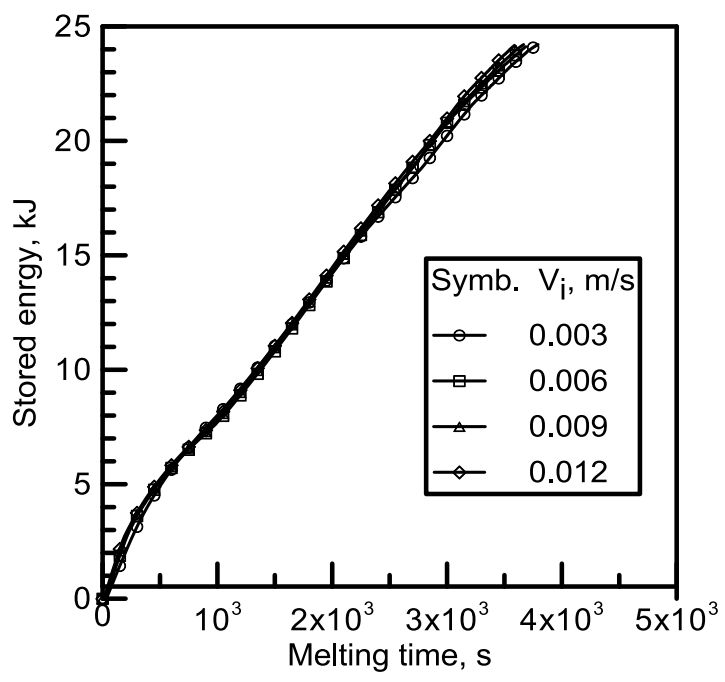

Fig.(13) Effect of HTF inlet velocity on PCM stored energy at constant HTF inlet temperature of $343 \mathrm{~K}$ and aspect ratio of 0.81 .

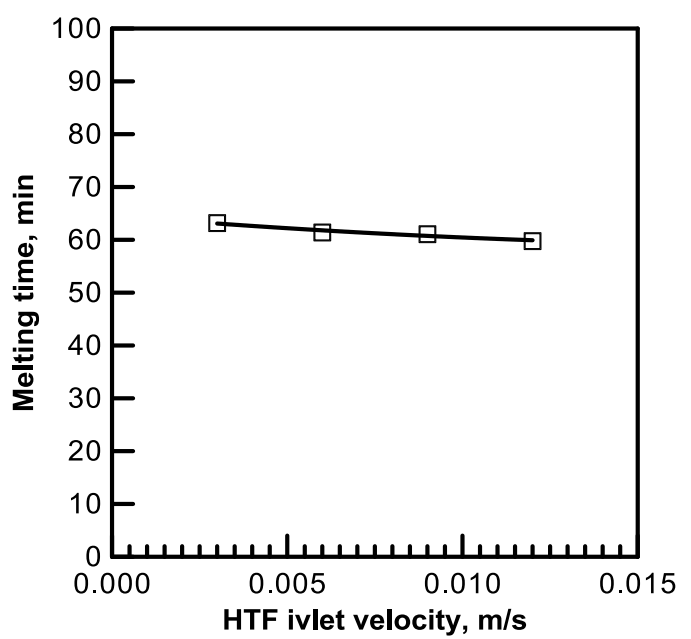

Fig. ( 14 ) Effect of HTF inlet velocity on PCM total melting time at Capsule aspect ratio of 0.81 and velocity of $0.003 \mathrm{~m} / \mathrm{s}$.

The relationship between total melting time and capsule aspect ratio is shown in Fig.18 for aspect ratio of 0.81 and HTF inlet velocity of 0.003 $\mathrm{m} / \mathrm{s}$. It is clear from the figure that the total melting time decreases with the capsule aspect ratio. This is due to the effect of capsule shape on the position of separation point which moves toward the trailing edge of the capsule permitting long contact between its surface and the flowing HTF before separation.

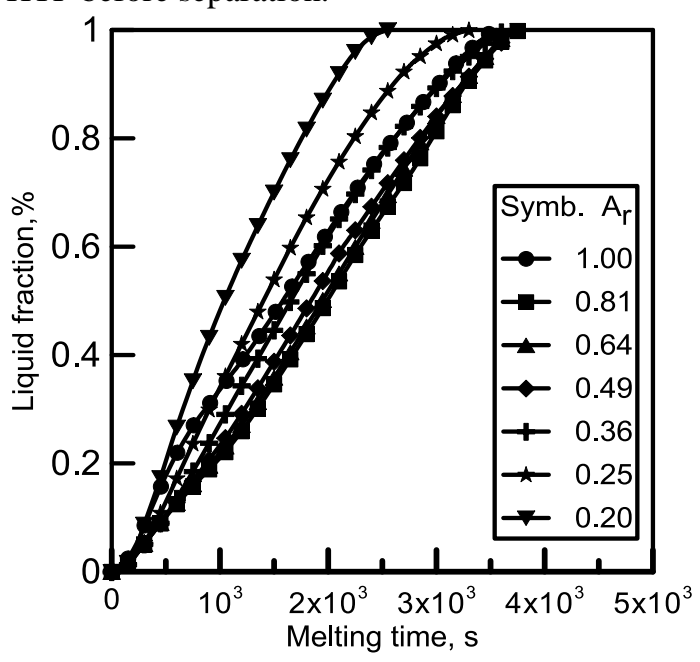

Fig.(15) Effect of Capsule aspect ratio $A_{r}$ on PCM liquid fraction at constant HTF inlet temperature of $343 \mathrm{~K}$ and velocity of $0.003 \mathrm{~m} / \mathrm{s}$.

\section{Conclusions}

From the above-discussed results of the process of paraffin wax melting inside elliptical cross-section capsules of different aspect ratio under HTF flowing with different inlet velocities and inlet temperatures, the following conclusions are made:

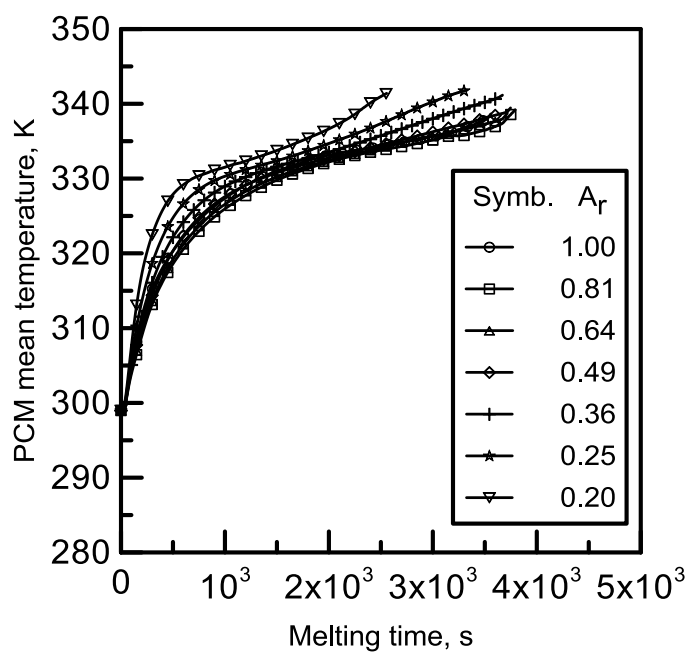

Fig.(16) Effect of Capsule aspect ratio $A_{r}$ on PCM mean temperature at constant HTF inlet temperature of $343 \mathrm{~K}$ and velocity of $0.003 \mathrm{~m} / \mathrm{s}$

The inlet temperature of the heat transfer fluid (HTF) has a great effect on the process of paraffin wax melting. The increase of HTF inlet temperatures increases the PCM liquid fraction and decreases at the same time the total time of melting the capsulated paraffin wax. 


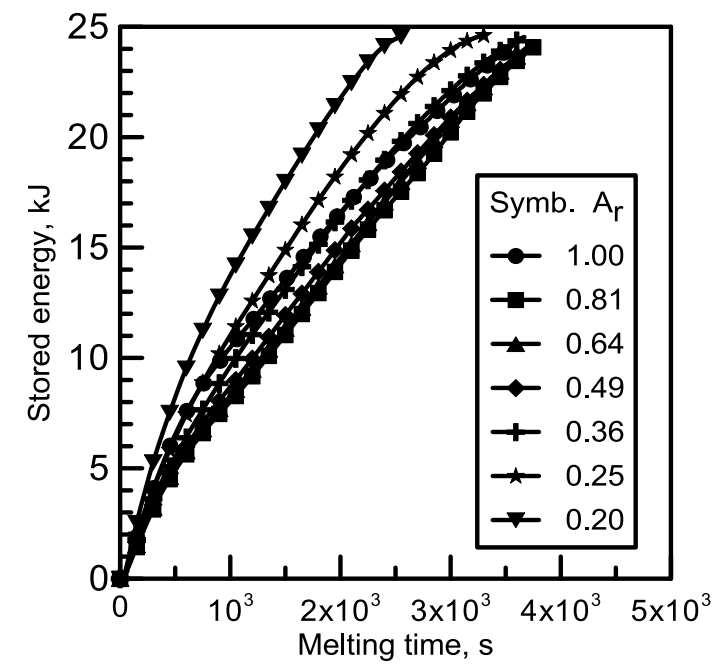

Fig.(17) Effec of Capsule aspect ratio $A_{r}$ at HTF inlet temperature of $343 \mathrm{~K}$ and velocity of $0.003 \mathrm{~m} / \mathrm{s}$.

The geometry of the capsule cross-section represented by its aspect ratio has a remarkable effect on the process of paraffin wax melting. Decreasing the aspect ratio of the capsule, i.e elongated the capsule in the direction of flow increasing the PCM liquid fraction and decreases the total time of melting the capsulated paraffin wax.

The increase of HTF inlet velocity has a very weak effect on the paraffin wax melting time.

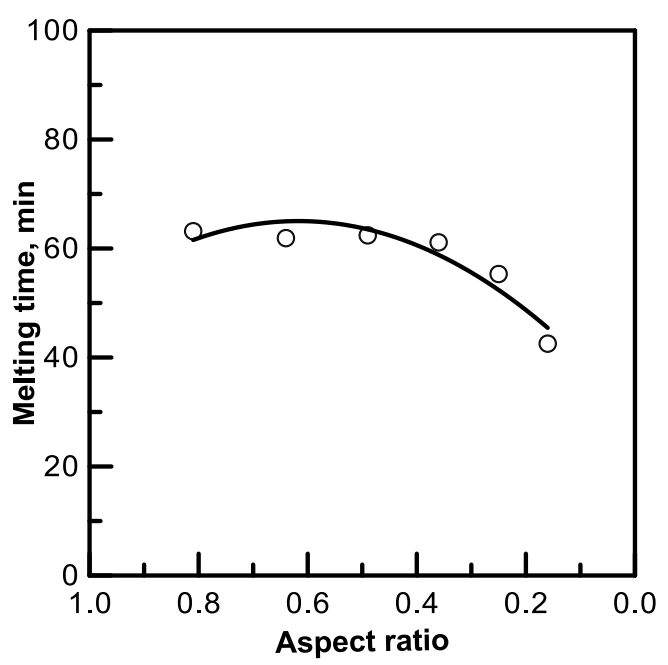

Fig.(18) Effect of Capsule aspect ratio $A_{r}$ on PCM total melting time at HTF inlet temperature of $343 \mathrm{~K}$ and velocity of $0.003 \mathrm{~m} / \mathrm{s}$.

\section{References}

[1] Kapsalis, V. and D. Karamanis, Solar thermal energy storage and heat pumpswith phase change materials. Applied Thermal Engineering, 2016: p. 1212-1224.

[2] Zalba, B., et al., Review on thermal energy storage with phase change: materials, heat transfer analysis and applications. Applied Thermal Engineering, 2003: p.251-283.

[3] Sharma, Atul, et al., Review on thermal and applications. Renewable and Sustainable Energy Reviews, 2009: p.318-345.

[4] Yang, J., et al., Experimental study on enhancement of thermal energy storagewith phase-change material. Applied Energy, 2016: p. 164-176.

[5] Wei J, Kawaguchi Y, Hirano S, Takeuchi H. Study on a PCM heat storage system for rapid heat supply. Applied Thermal Engineering 2005;25:2903-20.

[6] Kalaiselvam Siva , Marcel Xavier Lawrence and G. R. Kumaresh,(2010), Experimental and numerical investigation of phase change materials with finned encapsulation for energy efficient buildings, Journal of Building Performance Simulation, Vol. 3, No. 4, pp. 245-254.

[7] S. Kalaiselvam, M. Veerappan, A. Arul Aaron, S. Iniyan, Experimental and analytical investigation of solidification and melting characteristics of PCMs inside cylindrical encapsulation, Int. J. Therm. Sci. 47 (2008) 858-874.

[8] A. Felix Regin, S.C. Solanki, J.S. Saini, Latent heat thermal energy storage using cylindrical capsule: numerical and experimental investigations, Renew. Energy 31 (2006) 2025-2041.

[9] K. El Omari, T. Kousksou, Y. Le Guer, Impact of shape of container on natural convection and melting inside enclosures used for passive cooling of electronic devices, Appl. Therm. Eng. 31 (2011) 3022-3035.

[10] T. Saitoh, K. Hirose, High Rayleigh number solutions to problems of latent heat thermal energy storage in a horizontal cylinder capsule, ASME J. Heat Transf. 104 (1982) 545-553.

[11] H. Rieger, U. Projahn, M. Bareiss, H. Beer, Heat transfer during melting inside a horizontal tube, ASME J. Heat Transf. 105 (1983) 226-234.

[12] C.J. Ho, R. Viskanta, Heat transfer during inward melting in a horizontal tube, Int. J. Heat Mass Transf. 27 (1984) 705-716.

[13] H.S. Yoo, S.T. Ro, Numerical analysis of the phase change processes by coordinate transformations, Trans. KSME 10 (1986) 585-592. 
[14] A. Prasad, S. Sengupta, Nusselt number and melt time correlations for melting inside a horizontal cylinder subjected to an isothermal wall temperature condition, ASME J. Heat Tansf. 110 (1988) 340-345.

[15] Agyenim F, Hewitt N, Eames P, Smyth M. A review of materials, heat transfer and phase change problem formulation for latent heat thermal energy storage systems (LHTESS). Renewable and Sustainable Energy Reviews 2010;14:615-28.

[16] Muthukumar Palanisamy and Hakeem Niyas, Comparison of Thermal Characteristics of Sensible and Latent Heat Storage Materials Encapsulated in Different Capsule Configurations, https://www. researchgate.net /publication/320066441.

[17] Jones, B.J., et al., Experimental and numerical study of melting in a cylinder.International Journal of Heat and Mass Transfer, 2006: p. 2724-2738.

[18] E. Assis, L. Katsman, G. Ziskind, R. Letan, Numerical and experimental study of melting in a spherical shell, Int. J. Heat Mass Transf. 50 (2007) 17901804.
[19] F.L. Tan, S.F. Hosseinizadeh, J.M. Khodadadi, Liwu Fan, Experimental and computational study of constrained melting of phase change materials (PCM) inside a spherical capsule, Int. J. Heat Mass Transf. 52 (2009) 3464-3472.

[20] Sharifi, N., et al., Melting and solidification enhancement using a combined heatpipe, foil approach.

International Journal of Heat and Mass Transfer, 2014: p.930-941.

[21] V.R. Voller, C. Prakash, A fixed grid numerical modelling methodology for convection-diffusion mushy region phase-change problems, Int. J. Heat Mass Transf. 30 (8) (1987) $1709 \mathrm{e} 1719$.

[22] V.R. Voller, C.R. Swaminathan, General source-based method for solidification phase change, Numer. Heat. Transf. Part B Fundam. 19 (2) (1991) $175 \mathrm{e} 189$. 